Article

\title{
Porous Kirkenes: Crumbling Mining Town or Dynamic Port Cityscape?
}

\author{
Lukas Höller \\ Department of Urbanism, Delft University of Technology, The Netherlands; E-Mail: lukhoeller@gmail.com
}

Submitted: 30 January 2021 | Accepted: 10 May 2021 | Published: 27 July 2021

\begin{abstract}
The great number of actors in port city regions, such as port authorities, municipalities, national governments, private companies, societal groups, and flora and fauna, need to develop shared visions. Collaborative approaches that focus on combined values can help achieve long-term resilience and enable a sustainable and just coexistence of port and city actors within the same territory. However, the sheer focus on economic profit generated by port activities overshadows and ignores equally essential cultural, societal, and environmental values and needs. The lack of pluralities in planning and decision-making processes creates challenges for the cohabitation of the many actors and their interests within port-city regions. On the one hand, contemporary spaces in port cities cannot be classified and defined by traditional dichotomies anymore. On the other hand, the perception of spatial and institutional boundaries between port and city leads to a positivistic-driven definition of a rigid and inflexible, line-like interface physically and mentally separating the port from the urban activities and stakeholders, neglecting the inseparable character of many parts of our society. By investigating and re-imagining the future port-development plans within the historic mining town of Kirkenes, located around $400 \mathrm{~km}$ above the Arctic Circle in Northern Norway, the aim of this article is to explore and combine the concepts of negative and positive porosity and liminality and arrive at a renewed perception of the port cityscape, which can function as dynamic thresholds inbetween the multiple dualities and realities of various port and city actors. The article bridges the theoretical/conceptual sphere of urban porosity and the practical approaches of liminal design. By using Design Fiction as a tool for creating new, innovative, and pluralistic port city narratives, the article contributes to contemporary research that aims for imaginary, value-based, and history-informed approaches to designing future-proof, resilient, just, and sustainable port cities.
\end{abstract}

\section{Keywords}

borders; boundaries; Kirkenes; liminality; porosity; port cityscape; synergistic and adaptive ecosystems

\section{Issue}

This article is part of the issue "Planning for Porosity: Exploring Port City Development through the Lens of Boundaries and Flows" edited by Carola Hein (Delft University of Technology, The Netherlands).

(C) 2021 by the author; licensee Cogitatio (Lisbon, Portugal). This article is licensed under a Creative Commons Attribution 4.0 International License (CC BY).

\section{Introduction}

Next to the construction and expansion of infrastructure and facilities supporting the $24 / 7$ dynamic economic viability of a port, port cities need to accommodate urban functions that are crucial for an expanding city and its region (Hein, 2019). However, a healthy equilibrium within those complex, fluid, and ever-changing socio-spatial patterns in port cities has been disturbed by a growing imbalance of power and voice, leading to global elites engaging in exclusive decision-making processes in local places. Instead of explicitly categorized spaces, precisely defined by functions, clear bound- aries, and exclusive user groups, contemporary spaces in port cities unfold through multiple dichotomies, such as global-local; center-periphery, economy-culture, and economy-ecology. In order to accommodate a balance among those flows of materials, people, and ideas produced by the diverse port city actors and their needs, port city regions need to allow for urban porosity. As described by Wolfrum (2018), porosity is an analytical metaphor to describe the fragmentation of contemporary urbanized territories into borderscapes (Harbers, 2003) to accommodate diverse and interrelated flows of people, ideas, and resources migrating from one space to another. 
Nonetheless, decision-makers, academic experts, and planners all look at the many dualities, for example pollution-urban development, culture-production, or economy-climate change (PortCityFutures, n.d.) and the simultaneous realities of many actors (e.g., the port authority, national and regional governments, global maritime companies and local entrepreneurs, international visitors, inhabitants of different social ranks) as opposing and conflicting parts of spatially and institutionally separated entities. This creates further division, separation, and negative porosity, that is rigid and conflicting socio-spatial environments, within the urban territory. There is a need to identify, interpret, and highlight all the different stakeholders' values to define strategies and arrive at shared, just, and inclusive visions for a futureproof port-city development. The socio-spatial dimensions, the inevitable contradictions of coexistence, and the possibilities for collaboration of port and city actors remain under-investigated (Hein, 2020). Approaches to port cities from a holistic spatial planning perspective need to focus equally on spatial, institutional, social, and environmental resilience rather than addressing only technological or economic measures (Hein, 2011). Those new and creative imaginaries take place in between the multiple borders of a porous port cityscape.

The purpose of this article is to merge theoretical interpretations and conceptualizations of the porous port cityscape as the permeable fabric between port and city, with practical yet imaginative and creative design and planning approaches, in order to create and maintain urban porosity and accommodate societal and material flows and interactions without functional, spatial, and institutional separation, division, and exclusion. The main goal is to make sense of these porous spaces through spatial planning and design, which is operationalized by the concept of liminality (Turner, 1969). Liminality describes and utilizes the dialectics of cultural, political, temporal, social, historical, and natural dimensions and their coexistence in time and space that create the complex web of interrelations in port cities. A combined approach can help to turn the pores into flexible, open, and connective edges of the urban tissues between the port and the city. These pores-in-between spaces where different values, goals, and needs meet and often conflict-become an experimental and creative threshold space (Moretti, 2020) for synergistic collaboration among port city actors.

The first part of this article gives a broad overview of multiple conceptualizations of borders and porosity within the context of a transforming 'cosmopolitized' and 'networked' society from a sociological and geographical perspective. It explains how technological developments, globalization processes, and the changing socio-spatial and socio-economic compositions in port cities have led to the spatial and institutional separation of port and city entities. The article elaborates on the limitations of a 'false' dichotomy between port and city, which are thought of spatially and institutionally sepa- rated when in reality, port and city are inseparable due to their economic, cultural, and environmental impact on each other. The mutual impact provides a strategic base for planning and collaboration. Combining the two concepts of liminality and porosity is vital for underpinning the importance of a historically informed, place-based, and value-driven research and design framework. Such a holistic approach allows for creating new imaginaries of economically sound, socially just, and environmentally sustainable port cities. A goal of those new imaginaries is to question the status quo of decision-making in order to give voice to the otherwise unheard and excluded actors and to elaborate on how their social positions will inform the vision of 'their' port city (Luning et al., 2020).

The second part focuses on bridging the theoretical investigations of part one with the practical researchby-design approach elaborated in the case of Kirkenes, Norway. A synthesis of the author's master's thesis, this part of the article focuses on the operationalization of designing a 'liminal port cityscape' as a strategic socio-spatial environment that will help to re-imagine port cities as one synergistic and adaptive ecosystem. Uncertainties driven by climatic changes, the struggle of being trapped in a 'path dependency' (Hein \& Schubert, 2021) of mining history, and a multitude of strongly opposing values of global and regional economic powers, local indigenous cultures and traditions of the Sámi, and a broad section of society being torn in-between create the challenge for sustainable and inclusive development within the port cityscape of Kirkenes. Design Fiction (Bleecker, 2009), as a form of the scenario-building process, can be one of the tools through which spatial practices can mediate the cultural, economic, and ecological needs and values of all interrelated stakeholders in port cities. Within the overarching framework of research-bydesign (Roggema, 2016), Design Fiction offers freedom from outdated, monofunctional, and one-dimensional planning and decision-making concepts in port cities, often solely focusing on economic and technocratic criteria. Design Fiction, as a fusion of scientific facts, fictional narratives, and creative design, can become a tool to cut loose from practices that are obviously broken, unsuitable, and restricting and allow for new imaginaries (Bleecker, 2009). Finally, the design of additional value in the form of arising synergies between port and city actors and their different economic, cultural, and ecological values is translated into principles of planning and designing liminality in port cityscape, which can function as the basis for further research and projects.

\section{Borders, Porosity, and Liminality Within the 'Port Cityscape'}

\subsection{Fewer Boundaries, More Borders: The Duality of Porosity}

Borders in the form of tangible constructs-e.g., the physical built environment-and intangible ones- 
e.g., market forces, governance structures, and social identities-are manifestations of human ties and agencies. They depict the socio-spatial construct of the interdependence of the varying powers and influences of different actors. Increasing transnational flows of money, materials, humans, and ideas, driven by ongoing globalization and technologization, change how modern space is perceived. The so-called 'Spatial Turn' (Rumford, 2006) results in a chaotic and vast transformation of former traditional and dichotomous socio-spatial environments into complex porous spaces with blurry edges between them.

On the one hand, "we find ourselves faced with an extraordinary, little-noticed phenomenon: the explosion of spaces. Neither capitalism nor the state can maintain the chaotic, contradictory space they have produced" (Henri Lefebvre in Brenner, 2016). Globalization produces spaces/nodes of flows and creates a "space of flows" contradicting the "space of place" (Castells, 2000). The loss of measurable space, primarily through digitalization, global economic flows, mass mobility, the fluidity of identities, cultures, and societal constructs, and the dismantling of separating boundaries results in an increase in dualities within contemporary socio-spatial constructs.

On the other hand, the ongoing dismantling of separations creates an overproduction of borders (Moretti, 2017, p. 252). The new spatiality, in which the center and periphery of measurable economic, social, and cultural space become diffused, is characterized by simultaneous processes of reducing, thinning-out, multiplying, and doubling borders. Those processes of 'debordering and rebordering,' or 'waxing and waning' (Rumford, 2006) of borders, are a result of ever-changing socio-spatial flows and interrelations or porosity.

Those two identified phenomena, firstly the deconstruction of separating and impermeable boundaries, and secondly a new overproduction of borders due to an increase of interrelated flows and fixities, shed light on the character of porosity as a concept that describes the intricacy of socio-spatial environments. The growing porosity of borders, acting less like a boundary, and therefore the increased potential for many different actors to change, shift, and cross them creates a state of complexity within the urban space that allows for a diversity of identities and cultures and social interactions. The ambiguity of the multiple patterns of power, identity, and territoriality within the socio-spatial environment, shift the focus on the border as the conceptualized space itself by giving it a variable three-dimensional thickness. This positive connotation of porosity becomes the potential of the space to accommodate a balance between the interrelating tangible and intangible interests of economic, cultural, societal, and environmental flows and fixities.

Nonetheless, the sedimentation of unequivocally describable and manageable entities goes hand in hand with an increasing number of regional, even global, decentral, and autonomous levels of governance and power relationships. The result of sheer individualism created by this multiplication and doubling of the borders due to interrelated but conflicting agencies often do not seem to know commitment or good reason and finally disbands any form of collaboration from which might emerge common ground and commitment beyond individual benefit. From such a point of view, an increase in porosity can become the reason for renewed segregation and division, especially when governance and decision-making processes are unbalanced and within the power of elites. Therefore, the dominance of one-sided imaginaries of urban spaces leads to increased isolation, disconnected porous space, and the unheard voices and needs of ignored actors.

\subsection{The "Non-Place" Port and "Non-Port" City Interface}

Looking at port cities as porous and complex land/ sea-scapes, in which the port and its actors become a nodal point within a global network of flows and meets with cities' "space of place" (Castells, 2000), can show the two-sided edge the concept of porosity brings with it.

On the one hand, porosity can help describe the need for a flexible, permeable, and multi-functional urban fabric, allowing for connectivity and interaction across its borders and absorbing flows of people, materials, and ideas. Port and city once were a single integrated and non-divided entity, a unique phenomenon of maritime urban culture. No boundaries existed between the various functions diversely used by different actors at different times within the same space.

On the other hand, porosity in port cities is strongly related to the "efficiency and instrumentalization of reason" that comes with spatial and institutional separation of functions and governance (Wolfrum in Haenni, 2020). Within the past sixty years, when ports increasingly needed to compete within a globalized economic market, this spatial, functional, and administrative integrated symbiosis decayed. Innovations in cargo handling, like containerization, growing ship sizes due to increasing demand for goods and materials, and the technologization of infrastructures have led to the transformation of existing port structures and the emergence of new facilities in the outskirts of cities (Daamen \& van Gils, 2006; Hein, 2016; Pinheiro \& van Dijk, 2011). The exodus of ports out of host cities has gone hand in hand with the separation of port cities into two different administrative entities.

The transformation of the port into a node within a global economic network and the accompanied expansion of this network towards the maritime foreland and the regional hinterland shifts the focus of the port-city relationship away from the traditional waterfront towards the notion of 'scape' (Appadurai, 1990). The constant dismantling and the re-urbanization of obsolete port milieus within the city environment might have led to the reconnection of the city and the sea but it also supported the ongoing transition of port and city into two spatially and institutionally separated entities 
(Ducruet, 2011). The emerging administrative boundary creates a division between urban and maritime activities. The emerging port city interface (Hoyle, 1989, 2000) becomes an interactive economic system of openness and connectivity. However, it often creates the narrative of a localized, cross-sectional, and line-like administrative, spatial, and functional boundary between port and city, limiting collaborative governance and collective planning approaches among actors.

As a result, this 'false dichotomy' of port versus city, local versus global, economic versus social versus ecological, as separated and contradicting spatial and institutional systems, keeps port city actors, decisionmakers, and planners from seeing alternative relations, narratives, and new possibilities within this web of interrelated complexity. The contemporary decision-making processes between actors and the resulting developments of planners in port cities are defined by homogenous, measurable, and dividable, spatial, political, economic, cultural, and environmental contexts. Those contexts are "a polite but potent word in repressing anything that does not fit in" and therefore is "insuring that nothing sticks out, offends, or challenges" (Sennett, 2006). From an interpretive and designing perspective, the port city seems to get robbed of a milieu that allowed open structures, connectivity, and transition. These unique socio-spatial environments, which created a distinctly urban-maritime character or 'portuality,' as described by Moretti (2020), have become victims of a renewed separation and division and turns places into spaces lacking identity. The consequences are porous voids in the form of "non-place" ports and "non-port" places (Augé, 2008; Tang, 2012), caused by overdetermination and integration of the same, thus spatially separating the opposite.

\subsection{Liminality and Porosity: Betwixt and Between Port and City}

How can spatial research, planning, and design professions add to the already diverse and rich studies of port cities and use their strength as holistic professions combining social, political, cultural, environmental, and technical research skills with artistic and aesthetic representational ones? The rigid physical environment in port cities that evolved through many transformation processes can neither accommodate the ambiguous, plural, heterogeneous interrelations of actors nor a sustainable balance between economic, social, and ecological needs and values. Looking at urban porosity means looking at the 'betwixt and between,' the space of contradictions that creates frictions and opposition but has the ultimate potential to erode the rigid porous urban fabric of conflicts to create a permeable porous space of social, economic, and environmental interaction and collaboration.

Sennett (2006) calls those permeable pores 'ambiguous edges' that work as the interaction-space between the physical creation and social behavior of multiple city agents. Within this context, globalization and its impact on the urban form "deborders" the historical boundaries, the center, and the periphery of the port city and transforms the borders between port and city into a 'port cityscape' (Hein, 2011). Therefore, the focus needs to be set on a port city interface working as a liminal space (Hayuth, 1982). Such a perception accepts the ambiguity of time, space, human beings, or whole societal groups, resulting in 'Paradoxsynergy Scape' (Höller, 2020) or a threshold space of variable thickness (Moretti, 2017).

According to the anthropologist Victor Turner, the 'betwixt and between' or 'neither here nor there' leads to an in-between of two identities. Different from simply 'between,' this liminality, where socio-spatial environments have not yet transformed from one status to the other, ultimately focuses on the in-between place, trying to bridge the "what is," as the transition within space and the "what will be," as a transition in time (Turner, 1969). These scapes 'betwixt and between' port and city are filled with the heterogeneity and incomparability of different agents, their agencies, and their often oppositional and competitive values and interactions. This plurality describes the hybridity of spatial and temporal conflicts and their sensemaking, which is the inescapable reality when dealing with porous liminal spaces.

By combining the concepts of porosity and liminality, spatial planning can gain operative force in envisioning and imagining those porous spaces of "unnameable hybridity" (Koolhaas \& Mau, 1997, p. 969). Liminality allows for adapting to those fluid conditions within the porous fabric of the port city by experimentally manipulating the dualities and exploring the effect of interventions on the contemporary situation. Finding combined and shared values between the multiple imaginaries creates the opportunity for the coexistence of various stakeholders and for defining the port city as one 'Synergistic and Adaptive Ecosystem,' which is bigger than its parts. The design of those liminal porous scapes, being one of many possible solutions, rather than an ultimate masterplan, requires creative thinking to trigger unexpected, innovative, flexible, yet specific and carefully investigated hybridities within the spatio-temporal environment of the port cityscape.

\section{Switching Lenses: Research and Design of the 'Betwixt and Between'}

\subsection{Kirkenes as a Liminal Playground}

This section connects the theoretical and conceptual base and the liminal design approach of a future port city development within the case study city of Kirkenes. By combining the concept of porosity and liminality, the goal was to develop an imaginative and experimental, multi-scalar, and multi-perspective approach. This approach utilizes the conceptual shift from a simplistic and binary interface between port and city towards a complex port cityscape that widens the research and 
design perspective to include the liminality of the borders by giving them variable thickness and thresholds. It uses the fictional design framework of the Leiden-DelftErasmus Port City Futures Program, which emphasizes value-based approaches and focuses on understanding historic spatial-temporal transformations within the urban fabric in order to inform future design and planning decisions. The project elaborates on new maritime mindsets in the form of alternative urban development trajectories. Those fictional scenarios trigger and incentivize regional integration and synergy between ports as entry points into global dynamics and the city as a placespecific urban environment.

Researching port cities as open, pluralistic, and dynamic urban environments is a paradoxical, liminal process itself (Sennema, 2020). The project's first step was to identify the societal, economic, and natural actors by drawing, mapping, and describing the current landscape of various borders on land and sea. The Arctic, with its high contrasts of diverse natural and human actors, the need for economic development, and the necessity for climate change adaption, offers a unique variety of dualities, where the liminality of land- and sea-scapes becomes an indispensable factor in understanding the current configuration of the region.

The sparsely populated harbor town of Kirkenes, founded in 1905, is located more than $400 \mathrm{~km}$ above the Arctic Circle. Although now of relatively little economic significance, the former mining town near the Norwegian-Russian border has strategic importance. It is one of the main areas expected to change due to increas- ing navigability within Arctic maritime territories. As the self-claimed Capital of the Barents Region, Kirkenes is seen as becoming Europe's gate and a new logistic node in the soon-to-be ice-free Northern Sea-Route, creating a $40 \%$ faster trading route between Asia and Europe (Ministry of Transport and Communications, 2019, p. 4). As part of China's "Polar Silk Road" initiative, but also because of the growing international interest in oil and gas reserves within the Barents and Norwegian Seas, new development is planned for the port of Kirkenes, which currently serves the fishery and oil/gas industry within the Norwegian and Barents Sea and is a turningstation on the Hurtigruten Post-Boat cruise-ship route between Bergen and Kirkenes (Figure 1). Since the closure of the iron ore mine, the driver of the constant boom-and-bust economy and of urban development, the city has struggled to script legitimate scenarios for its future. Despite the efforts to reinvent Kirkenes and change its face from industrial development towards a future-proof Barents Region, historic and current mining and other industrial activities prevent the region from escaping its path dependency as a mining and industry town. Furthermore, many other stakeholders imagine a different future for Kirkenes, one of a future-proof, sustainable, and resilient port city that retains the region's remote character, rich in seemingly untouched nature in close relation to the well-being of the Sámi, the only officially recognized indigenous people in Europe, who have inhabited the territory for thousands of years.

As a second step, one needs to see the identified actors and their often conflicting values in close
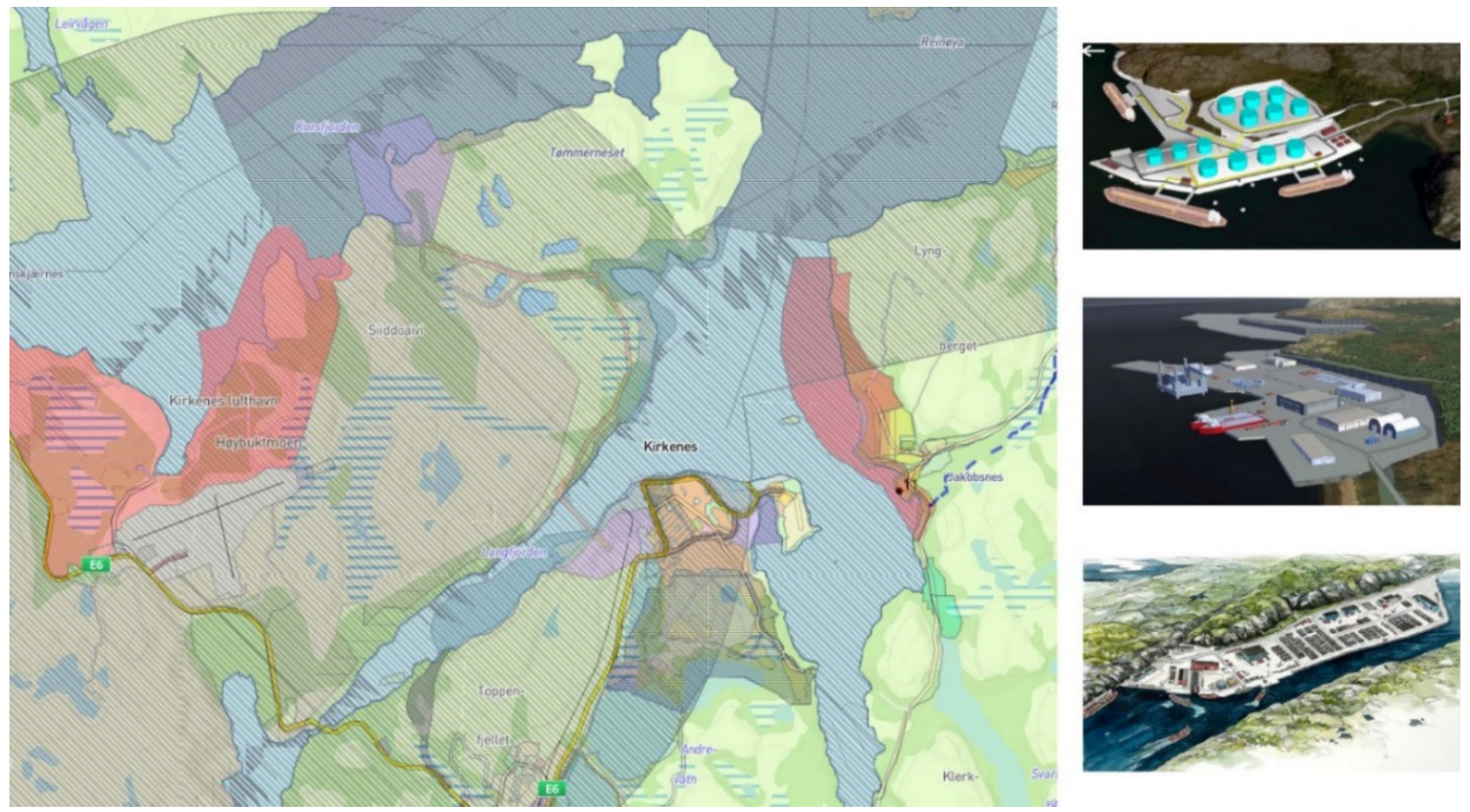

Figure 1. Extract of municipal map of Kirkenes showing the two last remaining options for the potential new port development at Leirpollen or Slambukta. Sources: Statens Vegvesen (2015) and Norconsult (2020). 
interrelation. Quantitative often positivistic data and numbers are essential for understanding administrative as well as technical, functional, environmental, economic, and cultural processes within port cities. Still, it is only possible to fully understand the interrelations when those data are set into a physical-geographical context. Therefore, mapping the actual place-specificity of the borders where the physical limits of two spatial territories coincide with the administrative one is pivotal (Hein, 2016). Together with the National Government, the municipality envisions a new and massive extraurban port development along the neighboring peninsula, transforming the currently small port into one of Scandinavia's biggest container ports, equivalent to the current capacity of the Port of Gothenburg (Höller, 2020).

Furthermore, logistic and supportive railway activities in the form of an internationally envisioned Arctic Railway (Ministry of Transport and Communications, 2019) will connect the proposed port in Kirkenes with Rovaniemi, Finland, and create access to trade flows towards the Baltic Hinterland and Western Europe. On the one hand, the opening of faster shipping routes between Europe and Asia and the increasing reachability of newly discovered and valuable fossil and mineral resources in land and sea, driven by global warming and its accompanying effects on the retreating sea-ice, is increasing the international interest for strategic port and maritime developments within Arctic territories. On the other hand, the regions' remote and natural state is endangered by this two-sided impact of natural changes and anthropogenic activities. Furthermore, a mismatch between the local needs of inhabitants and natural participants, e.g., the large variety of animal and plant communities, and global, primarily economic interests, pressuring and disturbing the often fragile socioecological system of the 'High North' creates further frictions and conflicts (Figure 2).

The planned port development in Kirkenes can be seen as the socio-spatial manifestation of the 'between' in the meaning of managing and regulating conflicts of spatially and institutionally separated entities, e.g. between the reindeer herding activity of the Sámi and the new port operation (Figure 3). However, the outsourcing of port infrastructure towards the coastline of the neighboring peninsula and the continuous dismantling of the port's milieu, which is currently embedded within the urban environment, weakens the perceived interrelation between port and city activities, needs, and goals. The physical as well as institutional separation of port and city disables spatial planning's ability to become a mediator for sensemaking between the different entities, their actors, and their corresponding values, goals, and wishes, even though overlapping values exist. The current municipal plan of the port infrastructure, where port and city are spatially disconnected and function as separated decision-making institutions, emerges an accumulation of singular territories. Those territories are divided by boundaries and create an impermeable, inflexible, and unbalanced socio-spatial port-city environment that supports the creation of friction and neglects the possibility of coexistence, collaboration, and synergistic partnerships within shared space.
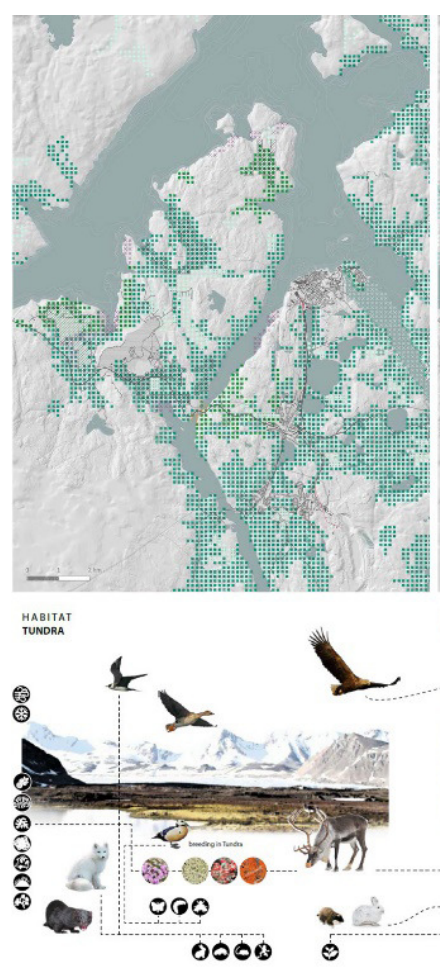

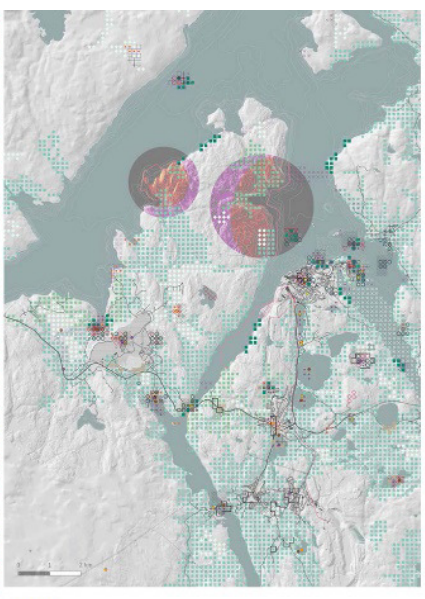

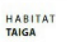

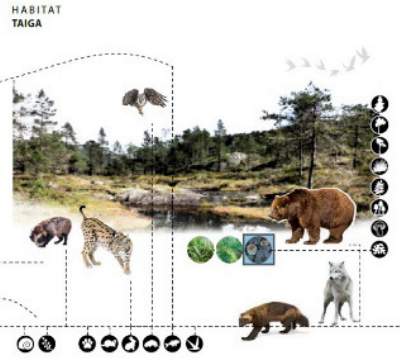

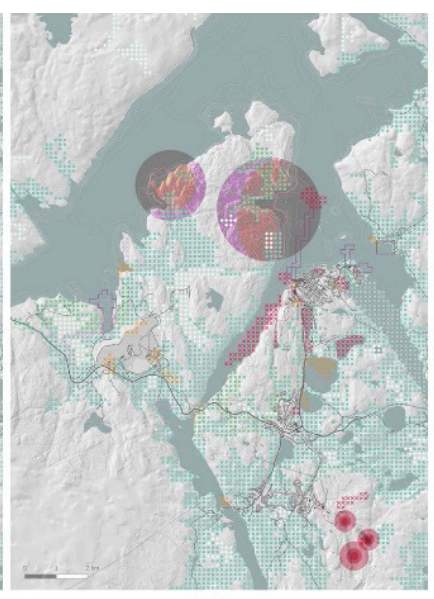

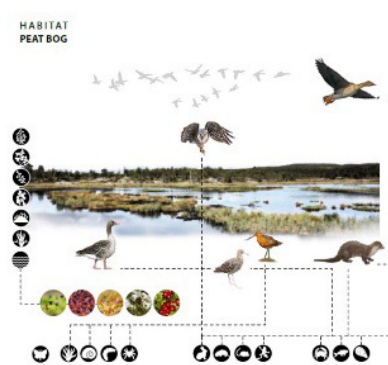

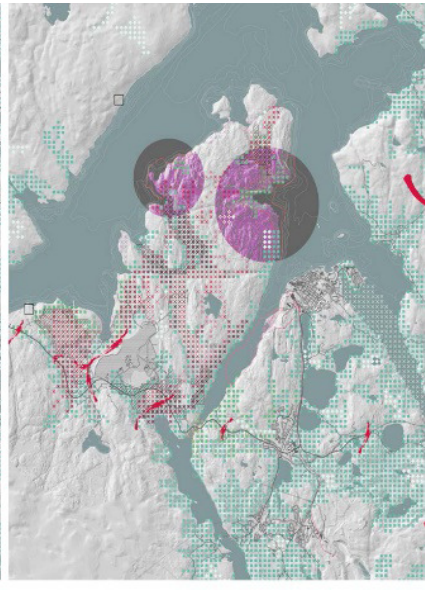

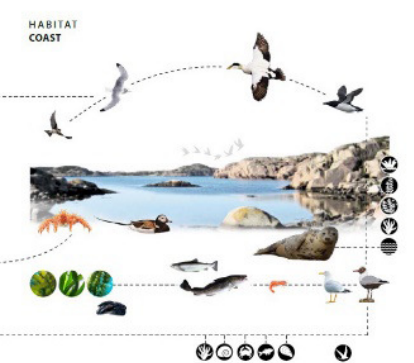

Figure 2. Series of maps overlapping different ecological territories with the friction area of the proposed port development by the municipality. Source: Höller (2020). 


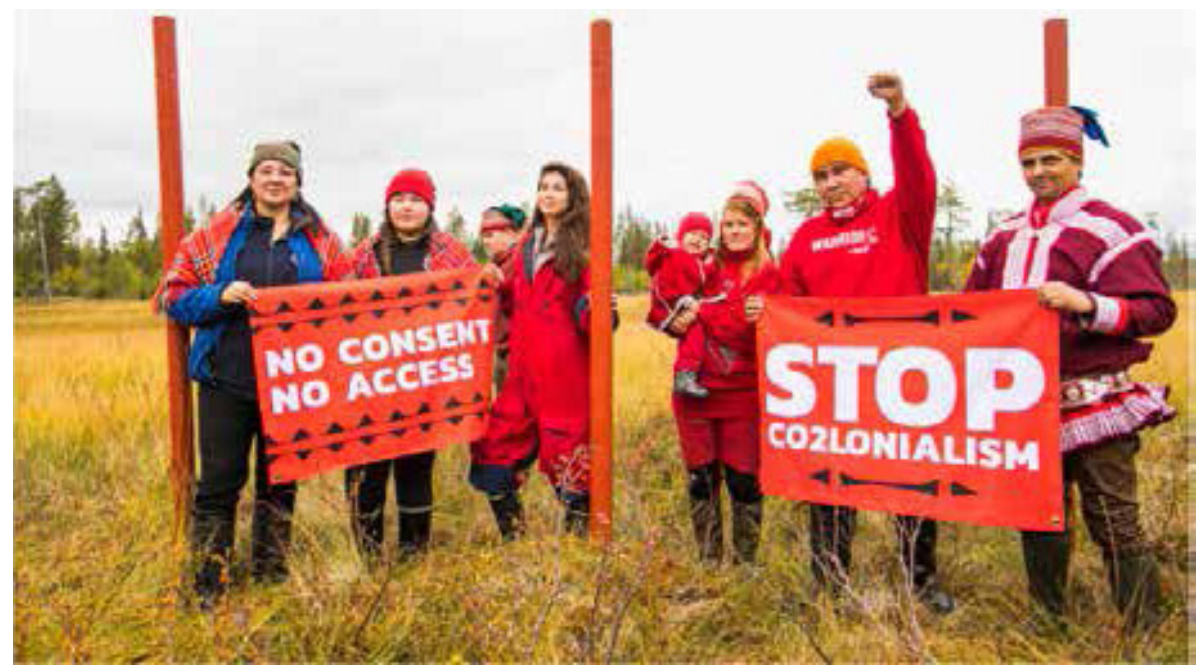

Figure 3. Cree leaders join an anti-Arctic Railway demonstration of the Sámi in Finland. Source: APTN National News (2018).

\section{2. 'Betwixt and Between' Friction and Fiction: Designing the Liminal}

It is unknown, thus science fiction provides opportunities for an epistemological version of a future in which it is known. (Larsen \& Hemmersam, 2018, p. 45)

The re-imagination of the port city of Kirkenes can profit from the concept of porosity and liminality. Such a reconceptualization can help develop imaginative mental images and experimental representations of alternative socio-spatial port city environments and help create a base for a new socially just, economically prosperous, and environmentally sustainable maritime mindset or 'portuality' (Moretti, 2020). The design proposes sociospatial environments that are neither part of the port's nor part of the city's territory allowing for multiple narratives, values, and needs of different port and city actors to coexist (Figure 4). By utilizing the concept of liminality, this approach bridges the 'what is there' and 'what is to come' to re-imagining the port cityscape of Kirkenes as flexible, innovative, temporally dynamic, and multilayered urban pores.

The most crucial step of the design process is to physically and mentally re-locate the globalized port back into its localized context, which increased the strategic and reflexive awareness for new possible forms of collaboration and coexistence of functions and values in time and space. The fictional design of the Port of Kirkenes works as a form of counter-mapping, allowing the territories of port and city actors to be redrawn so that actual liminal 'ParadoxSynergy Scape' in-between their edges can occur (Höller, 2020). The main proposal is a floating port structure located between Kirkenes' current waterfront and the coastline of the neighboring peninsula, where the municipality officially proposed the port. This step is essential in giving thickness and consistency to the porous space in between sea and land that becomes the liminal accumulation zone of the imaginative and cre- ative richness of the new 'portuality.' Intentionally juxtaposing contradicting elements within Kirkenes' land/ sea-scape initiates a sensemaking process that allows for a gradual transition in between two or more port city realities. Implementing a floating port as a design concept creates new spaces for coexistence, collaboration, and synergy between the various dualities. This conceptual decision led to four unique, explorative, and synergistic new port cityscape: the Floating Port, the Reindeer-Energy Port, the Urban Port, and the Wetland Port (Figure 6).

\subsubsection{Floating Port}

The Floating Port (Figure 5) functions as the overarching and connecting conceptual construct and allows for the emergence of the other three land-sea, port-city, global-local 'ParadoxSynergy Scape.' The floating structure also combines multiple technological innovations aimed at increasing capacity, adaptability, and flexibility for global maritime trade, with ecological adaptation strategies that focus on a healthy local coastal environment. Using underwater storage facilities for containers, the compactness can reduce the use of land by otherwise large-scale logistic infrastructures. The principle of creating flexibility and open endings in design anticipates the need to adapt to future economic or environmental changes and challenges. For example, a floating port can be easily dismantled and shipped to newly emerging and more essential trading grounds, e.g., deeper in the Arctic maritime territory. Also, technological progress, such as transforming containers into the actual shipping and logistic device itself, can lead to new development strategies. The storage of containers at local port facilities is no longer necessary; thus, such obsolete space can be made useable for other port city functions. In such a future projection, the underwater container storage used as infrastructure within the global value- and logistic chain of port activities can now be reused as an 


\section{COGITATIO}

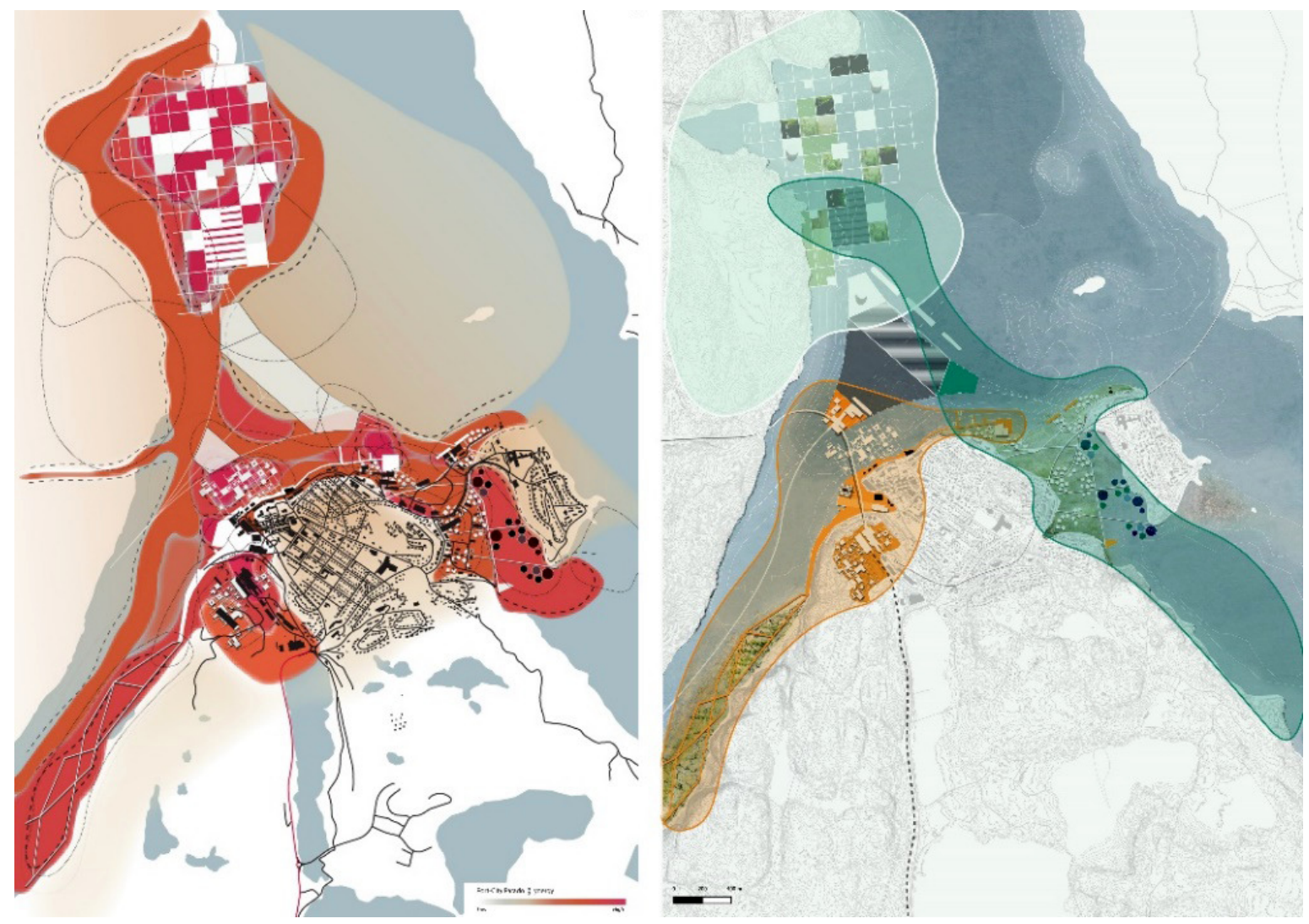

Figure 4. The synergistic interrelations between local specificities of the city and its surrounding and the port, resulting in a multiple set of spatial and temporal implementations and interventions. Source: Höller (2020).
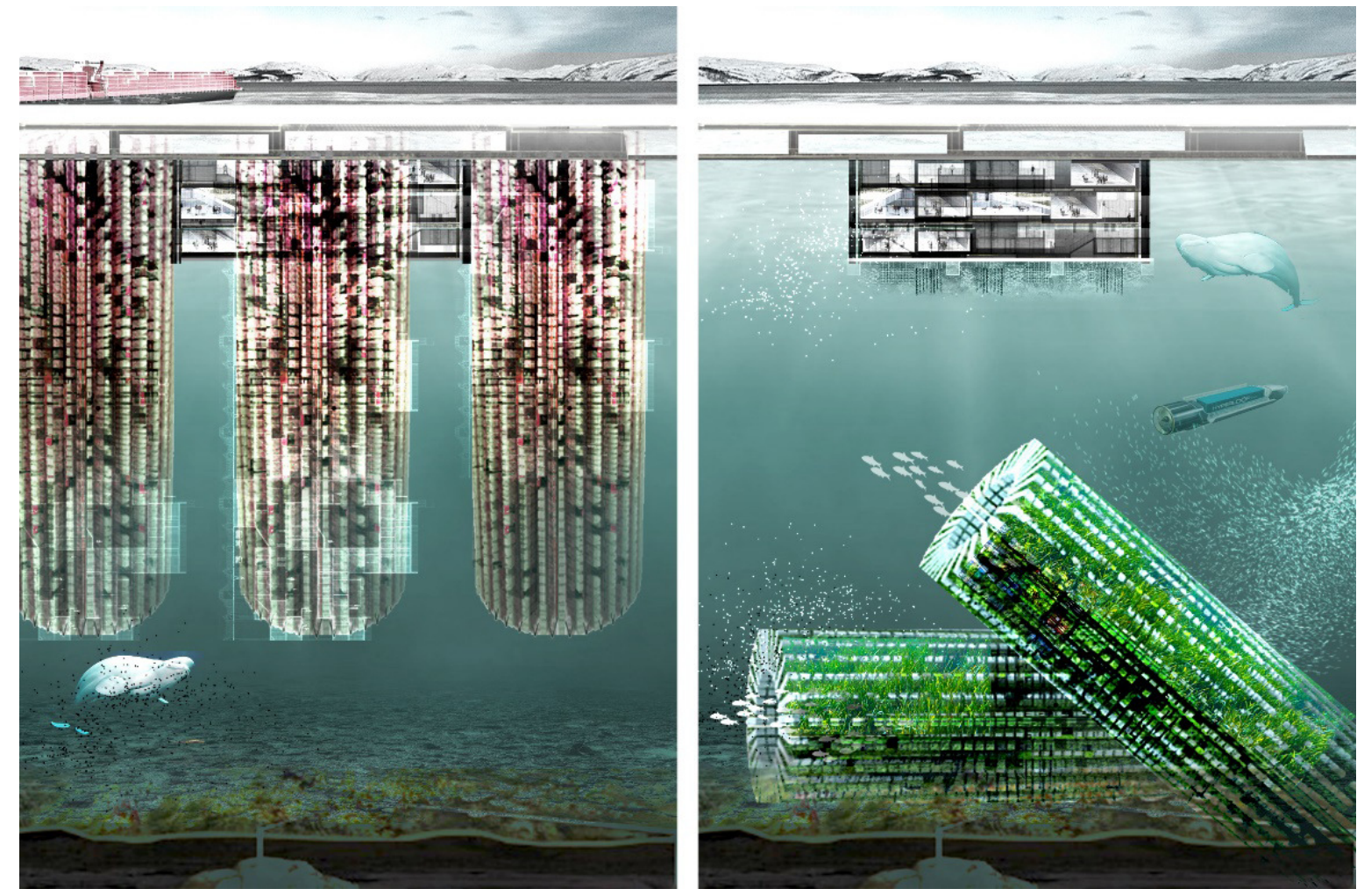

Figure 5. Imaginative and fictional design of the proposed floating port transforming from container-storage to an artificial reef for the aquatic ecosystem. Source: Höller (2020). 
artificial reef to support local maritime flora and fauna. By connecting the global values of maritime trade with the local goal of an adaptive, flexible, and environmentally sustainable coastal region, the contradicting liminalities interrelate through space and use. However, they are separated by the factor of time. This hybridity creates liminal scapes in between the needs of different port city actors by including design strategies that focus on a future transition of space, technology, and flows from the port to the city sphere.

\subsubsection{Reindeer-Energy Port}

The first of the three emerging imaginative liminal spaces is the Reindeer-Energy Port, located along the land-sea continuum between the floating port structure and the Tømmerneset Peninsula. This port cityscape's liminal and pluralistic character derives from the land-use conflict between local/regional reindeer herding activity and the proposed development of the port and logistic facilities along the peninsula. The spatial design imagines a port city environment where the contradicting and currently conflicting dualities of the local cultural and economic practice of reindeer herding, a vital part of the indigenous Sámi's socio-ecological livelihood, and the proposed global maritime activities can coexist and even create synergistic values for each other. On the one hand, the specific symbiosis of algae and fungus is an essential winter food source for the reindeer, currently becoming scarce because of climatic and pollution impacts. On the other hand, the symbiosis mechanism functions as a potential natural producer for hydrogen to potentially fuel ships with a sustainable alternative to fossil oils in the near future.

The Design Fiction equips the edges between the port facility and grazing ground with a Floating Lichen Farm. The intervention bridges the spatial and institutional sphere of reindeer herding and grazing on land with the artificial farming of lichen for nature-based hydrogen production. The design provides a space of coexistence and synergy production between the Sámi and their reindeer as cultural and ecological stakeholders, the new technological production of sustainable fuels for maritime logistic and shipping companies, and the economic distribution of alternative energies by the municipality. Based on the different spatio-temporal dynamics of reindeer herding, which mainly takes place on this specific location in the winter months, and maritime shipping activities, which mainly peak in summer, due to retreating Arctic sea ice, the Floating Lichen Farms are used by different actors for different activities during different temporal segments. This form of liminal design allows the port cityscape to change its spatial form and size and the occupation by different actors and their related activities depending on different periods. In the winter, space is used as an additional reindeer herding and migration area. Part of the Floating Lichen Farm functions as grazing and sheltering space for the reindeer.
During the summer, the platform works as a hydrogen production facility and functions as a recreational and tourist hot spot within the artificial land-sea ecosystem between the lichen farms. Such a temporally separated but spatially shared use of territory needs institutional collaboration and integrated planning.

\subsubsection{Urban Port}

The second 'ParadoxSynergy Scape' of the new synergistic and adaptive port city ecosystem of Kirkenes is the Urban Port. Here, multiple dualities between the global and local port and city actors as well as their economic, cultural, and environmental activities create the liminal design of the socio-spatial environment. The new narrative aims for new, future-proof and hybrid configurations of port operations that can be integrated with the city's urban fabric, allowing for coexistence and creating mutual benefits and shared values. First, the design proposes a new cruise ship terminal as part of the floating port, which serves the needs of global tourism, which plays an essential economic role for the region in and around Kirkenes. The new multimodal transport hub connects the various sea-and land-based transport infrastructures, such as cruise ships, regional ferries, the mining train potentially being redeveloped for local commuting, and the newly proposed Arctic Hyperloop into the Norwegian and Finish hinterland as an alternative to the proposed Arctic Railway. As a local centerpiece, a floating extension is proposed of the urban residential area, in the form of housing and recreational activities in between the global cruise ship terminal and the local waterfront.

Embedding global tourism and mobility functions in the city's local context allows for renewed multifunctionality and ambiguity of the port city milieu. The permeable and porous in-between scapes can accommodate shared or combined activities. Spatially and temporally layering those activities allows for the coexistence of non-integrable port and city values and achieves a compact spatial development. Furthermore, the design transforms flows of resources and materials from global into local value chains and vice versa. The new narrative looks for the transition of the current function of the port, which functions as a bulk port for iron ore and as a service and maintenance port for regional fishing and maritime oil and gas exploitation, into a makers' district that focuses on circularity and the re-purposing of global resource flows for local usage. One example is the re-purposing of mining waste, which is currently dumped into a nearby fjord and causes environmental problems: They are used as building materials for the local construction industry. Within such a development strategy, the infrastructure and facilities of the mine and the bulk port, which also have significant cultural importance, can be reused to become a circularity hub. Simultaneously, the former dumping side along the fjord can be gradually re-natured and used as an 


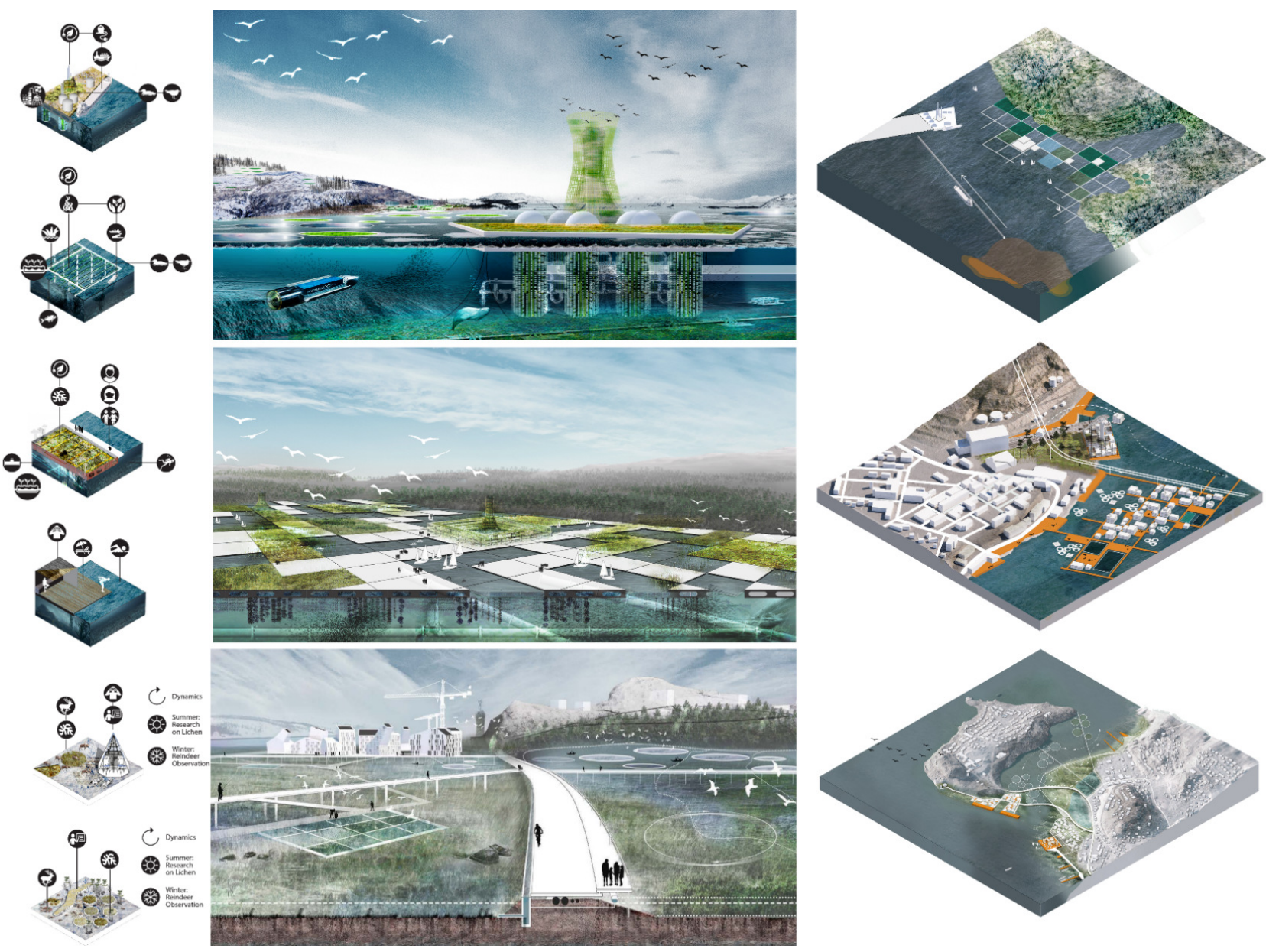

Figure 6. Visualizations of the three "ParadoxSynergy Scapes": Reindeer-Energy Port, Urban Port, and Wetland Port. Source: Höller (2020).

artificial beach for recreation and eco-tourism. Another example is the reuse of the obsolete dry-dock and repair hall. While the new dry-dock will be relocated towards the floating port structure, the old facility can re-purpose global maritime scrap materials and recycled shipbuilding resources. Those can be used to produce urban building blocks for the local floating residential area and the makers' district, using the culturally significant but obsolete maintenance crane as a device for self-adaptation.

\subsubsection{Wetland Port}

The Wetland Port is the third and last area envisioned during the fictional design. The strategy aims for the notion of port cities as natural ecosystems and highlights their interrelation with maritime and coastal natural and cultural resources. The design envisions a liminal port cityscape where fishing activity gradually shifts from being part of a global/international economic activity in marine or coastal areas of the Barents Sea to being part of the local culture and livelihood of independent fishers. The area between Kirkenes and the Prestoya Peninsula, which has been reclaimed for the development of port facilities and other commercial activities, will be re-natured as an intertidal wetland, interconnecting local and global fishing, local living, and global tourism and it will function as a new artificial ecosystem for maritime and terrestrial plant and animal communities. The proposed production of fish, algae, and other maritime products for regional and local supply allows combining flows of humans and resources from both spheres and integrating them into one liminal design. One of the main design decisions is the development of a food hub located on one of the obsolete quays, which encounters the floating fishing hub used for commercial and large-scale fishing activities. On the one hand, this hub can accommodate international fishers, mainly from Russia, and bring them and their product closer to the local inhabitants and global tourists. The food hub can be used as a square for weekly markets and events. On the other hand, local food producers can use the food hub to distribute and sell the unique and local seafood products that the algae and fishing aquaculture will produce within the re-natured intertidal wetland to local and global end-consumers. The global maritime shipping industry's waste products-e.g., greywater and food waste from cruise ships and waste from the commercial fishing industry - will be cleaned and reused as nutrients 
for local seafood production. The new wetland works as a living machine, a nature-based wastewater regeneration facility that helps to circularize waste flows, offering service, production-related, recreational, and environmental value to global and local port and city actors equally.

\section{Conclusion}

Looking at port-cities through the combined lens of porosity and liminality can help elaborate the translation of conceptual elements and finally arrive at principles and strategies that can help plan and design flexible, innovative, connected, and permeable 'Port Cityscape' (Hein, 2011). Those new imaginative and liminal hybrid spaces profit from the dynamic, multi-scalar, and complex relationships of economic, environmental, cultural, and political actors and institutional decision-makers. The careful sensemaking of relationships in the form of a physical design and governance strategies enables the port city to become more than the sum of single elements and allows it to withstand the uncertainties and create future-proof synergistic opportunities. Approaching the port-city as a complex land-/sea-scape from a spatial perspective makes it possible to overcome universalizing outdated approaches and monofunctional developments that have been mainly focused on managing separated port and city entities. By gradually elaborating on the theoretical and conceptual elements of porosity and liminality, the article makes a methodological shift away from mainly focusing on rigid and inflexible line-like boundaries between port and city towards port-cities "as [a] system or as a concept or as a series of mechanisms that, collectively and individually, link port and city" (Hoyle in Moretti, 2017, p. 251). By elaborating on the dualities and resulting synergies between different agents and by investigating flows and dynamics instead of focusing strictly on either the city, the port, or the ecological shifts, the focus is on the in-betweenness of port and city and spotlights the port city relationship as the result of many pluralistic, contradicting, heterogenic, complex and often confusing social, economic, and environmental dynamics: "Instead of thinking of places as areas with boundaries around, (places) can be imaged and articulated moments in networks of social relations and understandings "(Massey in Raffestin, 2012, p. 126). The article's conceptual and practical investigation of port city liminality and the gradual threshold between different physical and non-physical realities represents only one experimental approach dealing with the exploration and re-imagination of future port cities. However, there is a need for more experimental and imaginative projects focusing on port cityscape as porous and fluid 'scapes,' that combine theoretical/conceptual work with practical, designing, and planning approaches. Spatial planners, as part of a holistic and interdisciplinary team of professionals, can help translate and facilitate the needs of all heard and especially unheard stakeholders to create a future- proof built environment that goes beyond the paradigm of the waterfront. Spatial planners can thus redefine port-city-region relationships worldwide. Spatial planning as holistic, maybe even liminal professions can become the mediator between the many local and global stakeholders, including human/natural inhabitants, economic entrepreneurs, and academic professionals, thus gaining operational power to help research and design future, sustainable, and adaptive port cityscape.

\section{Acknowledgments}

I want to thank Carola Hein, Professor and Head of the Chair History of Architecture and Urban Planning, Delft University of Technology, for sharing her enormous insight and knowledge on port cities and her comments that greatly improved the quality of this paper. Furthermore, I want to thank Fransje Hooimeijer, Associate Professor Environmental Technology \& Design, Delft University of Technology, who, together with Carola Hein, supervised my master thesis on Kirkenes. Lastly, I want to acknowledge that this paper is part of a bigger collaborative and shared research approach of the Leiden-Delft-Erasmus (LDE) Research Program PortCityFutures.

\section{Conflict of Interests}

The author declares no conflict of interests.

\section{References}

Appadurai, A. (1990). Disjuncture and difference in the global cultural economy. Public Culture, 2(1), 1-24. https://doi.org/10.1177\%2F026327690007002017

APTN National News. (2018, September 6). Cree leaders join anti-railway demonstrations in Finland. https://aptnnews.ca/2018/09/06/cree-leaders-joinanti-railway-demonstrations-in-finland

Augé, M. (2008). Non-places: Introduction to an anthropology of supermodernity. Verso.

Bleecker, J. (2009). Design Fiction: A short essay on design, science, fact and fiction. Near Future Laboratory. http://blog.nearfuturelaboratory.com/2009/ 03/17/design-fiction-a-short-essay-on-designscience-fact-and-fiction

Brenner, N. (2016). The hinterland urbanised? Architectural Design, 86(4), 118-127. https://doi.org/ 10.1002/ad.2077

Castells, M. (2000). The rise of the network society (2nd ed.). Blackwell Publishers.

Daamen, T. A., \& van Gils, M. (2006, November 5-9). Development challenges in the evolving port-city interface: Defining complex development problems in the european main sea-port-city interface: Rotterdam and Hamburg [Paper presentation]. IACP 10th International Conference Cities and Ports, Sydney, Australia. 
Ducruet, C. (2011). A metageography of port-city relationships. In J. J. Wang, D. Olivier, T. E. Notteboom, \& B. Slack (Eds.), Ports, cities, and global supply chains (pp. 157-172). Ashgate.

Haenni, S. (2020). Introduction: The porous city. Mediapolis, 5(1). https://www.mediapolisjournal.com/ 2020/02/introduction-porous-city

Harbers, A. (2003). Borderscapes: The influence of national borders on European spatial planning. In R. Brousi, P. Jannink, W. Veldhuis, \& I. Nio (Eds.), Euroscapes (pp. 143-166). Must Publishers/ Architectura et Amicitia.

Hayuth, Y. (1982). The port-urban interface: An area in transition. Area, 14(3), 219-224. http://www.jstor. org/stable/20001825

Hein, C. (2011). Port cities: Dynamic landscapes and global networks. Routledge.

Hein, C. (2016). Port cities and urban waterfronts: How localized planning ignores water as a connector. WIREs Water, 3(3), 419-438. https://doi.org/ 10.1002/wat2.1141

Hein, C. (2019). The port cityscape: Spatial and institutional approaches to port city relationships. PORTUSplus, 8(Special Issue). https://portusplus.org/index. php/pp/article/view/190

Hein, C. (2020). Port city resilience: (Re-)connecting spaces, institutions and culture. PortCityFutures. https://www.portcityfutures.nl/news/port-cityresilience-re-connecting-spaces-institutions-andculture

Hein, C., \& Schubert, D. (2021). Resilience and path dependence: A comparative study of the port cities of London, Hamburg, and Philadelphia. Journal of Urban History, 47(2), 389-419. https://doi.org/ 10.1177/0096144220925098

Höller, L. (2020). Dynamic port-city scapes: From liminal "non-places" to imaginative and synergistic adaptive ecosystems [Master's thesis, Delft University of Technology]. http://resolver.tudelft.nl/uuid: 5bd2f042-74d1-4dc1-903d-dbe2d49f9f79

Hoyle, B. (2000). Global and local change on the port-city waterfront. Geographical Review, 90(3), 395-417. https://doi.org/10.2307/3250860

Hoyle, B. S. (1989). The port-city interface: Trends, problems and examples. Geoforum, 20(4), 429-435. https://doi.org/10.1016/0016-7185(89)90026-2

Koolhaas, R., \& Mau, B. (1997). What ever happened to urbanism? In R. Koolhaas \& B. Mau (Eds.), S, M, L, XL: O.M.A. (pp. 959-971). 010 Publishers.

Larsen, J. K., \& Hemmersam, P. (Eds.). (2018). Future North: The changing Arctic landscapes. Routledge. https://doi.org/10.4324/9781315583716

Luning, S., Littlejohn, A., \& Hein, C. (2020). Cultural anthropology, infrastructures and envisioning futures. PortCityFutures. https://www. portcityfutures.nl/news/cultural-anthropologyinfrastructures-and-envisioning-futures

Ministry of Transport and Communications. (2019). Final report of the joint working group between Finland and Norway on the Arctic railway. Helsinki.

Moretti, B. (2017). Port city borderscapes: Origin, nature and evolution of the administrative boundary. In G. Pellegri (Ed.), De-sign environment landscape city (pp. 251-262). David and Matthaus.

Moretti, B. (2020). Beyond the port city: The condition of portuality and the threshold concept. JOVIS Verlag $\mathrm{GmbH}$.

Norconsult. (2020). Rapport om stamnetterminal på Slambanken/KILA og Leirpollen Sør er lagt frem [Submitted report on the main network terminal at Slambanken/KILA and Leirpollen Sør]. https://www. sor-varanger.kommune.no/getfile.php/4732665.652. ubmsiqsnqa7awu/20200831+SVK_Forstudierapport +stamnetterminal+\%28879256\%29.pdf

Pinheiro, M., \& van Dijk, H. (2011). Failure or success: The impact of industrialisation and de-industrialisation on port cities in Europe [Paper presentation]. Conference "O Mar, Identidades e Patrimónios," University of Porto, Portugal.

PortCityFutures. (n.d.). Dualities. https://www.portcity futures.nl/dualities

Raffestin, C. (2012). Space, territory, and territoriality. Environment and Planning D: Society and Space, 30(1), 121-141. https://doi.org/10.1068/d21311

Roggema, R. (2016). Research by design: Proposition for a methodological approach. Urban Science, 1(1), 2. https://doi.org/10.3390/urbansci1010002

Rumford, C. (2006). Theorizing borders. European Journal of Social Theory, 9(2), 155-169.

Sanchez, J. M. P. (2019). Discussing the port-city relationship: What can we expect from the future? The Port and the City. https://theportandthecity.wordpress. com/2019/01/22/discussing-the-port-cityrelationship-what-can-we-expect-from-the-future

Sennema, H. (2020). What's in a name? Re-thinking port cities as systems. PortCityFutures. https://www. portcityfutures.nl/news/whats-in-a-namere-thinking-port-cities-as-systems

Sennett, R. (2006). The open city. Urban Age. https:// urbanage.Isecities.net/essays/the-open-city

Statens Vegvesen. (2015). KVU: E6 HøybuktmoenKirkenes, Juni 2015 [KVU: E6 HøybuktmoenKirkenes, June 2015]. https://www.regjeringen.no/ contentassets/3776bd87778541c69698f510e545d 313/kvu_e6_hoybuktmoen_kirkenes.pdf

Tang, Q. H. (2012). "Non-place" ports and "non-port" places: The sustainable port-city interface, Part $I$. IDEASWA. http://www.ideas.swagroup.com/nonplace-ports-and-non-port-places-the-sustainableport-city-interface-part-i

Turner, V. (1969). Liminality and communitas. In V. Turner (Ed.), The ritual process: Structure and antistructure (pp. 94-113). Aldine Publishing.

Wolfrum, S. (2018). Porous city: From metaphor to urban agenda. Birkhäuser. https://doi.org/10.1515/ 9783035615784 


\section{COGITATIO}

\section{About the Author}

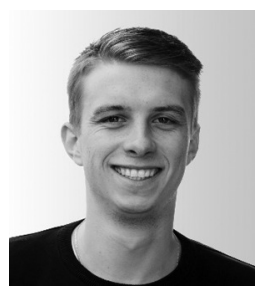

Lukas Höller holds a B.Eng. in Landscape Architecture from Weihenstephan-Triesdorf University of Applied Sciences and finished his M.Sc. in Architecture, Urbanism and Building Sciences, and Track Urbanism at Delft University of Technology with Cum Laude in 2020. He will start his PhD research on "Second-tier Port Cities as Gateways to Sustainable Urbanization" at the Delft University of Technology Urbanism Department, Section of Spatial Planning \& Strategy, in September 2021. He is also part of the Leiden-Delft-Erasmus PortCityFutures research group and is involved in several research and planning activities. 